\title{
Review: Role of microRNAs during spermatogenesis in mammals
}

\author{
Mujahid Ali Shah, Chuanfei Xu, Shixin Wu, Kifayatullah, Chuanping \\ Yi, Wangsheng Zhao, Asma Baber and Xin Cai* \\ School of Life Science and Engineering, Southwest University of Science and Technology, Mianyang 621010, \\ Sichuan-China \\ *Corresponding author's email: caixin2323@126.com \\ Citation \\ Mujahid Ali Shah, Chuanfei Xu, Shixin Wu, Kifayatullah, Chuanping Yi, Wangsheng Zhao, Asma Baber and \\ Xin Cai. Review: Role of microRNAs during spermatogenesis in mammals. Pure and Applied Biology. Vol. 7 , \\ Issue 2, pp819-831. http://dx.doi.org/10.19045/bspab.2018.700101
}

\begin{tabular}{llll}
\hline \hline Received: 27/03/2018 & Revised: 08/06/2018 & Accepted: 21/06/2018 & Online First: 29/06/2018 \\
\hline \hline
\end{tabular}

\section{Abstract}

The spermatogenesis in mammals comprises three stages: the mitotic proliferation of spermatogonia, meiosis of spermatocyte, which produces haploid spermatids, and spermiogenesis which leads spermatozoa into the tubule lumen. Each step of spermatogenesis is controlled by a number of factors including microRNAs (miRNAs) for the regulation of gene expression, these single-stranded non-coding small RNAs molecules contains about 19 25 nucleotides. Since first miRNAs (Let-7 and lin-4) were discovered in Caenorhabditis elegance, thousands of miRNA have been identified from different species in the past 23 years. It has been reported that the miRNAs function as guide molecules in post-transcriptional regulation by base pairing with target messenger RNA (mRNA) and lead to cleavage or translational repression. Recently, several pieces of evidence suggested that the miRNAs are closely related to the spermatogenesis by the analyzing mRNA changes in testicular tissue from different animal species. The present review has summarized the recent progress on the role of miRNAs during spermatogenesis which may contribute to understate the spermatogenic arrest in mammals.

Keywords: Gene expression; Infertility; MicroRNAs; Spermatogenesis

\section{Introduction}

Spermatogenesis is a process in which the male germ cells are produced by complex processes of cellular differentiation and proliferation occurring inside the seminiferous tubules of testis [1]. In detail, the complex processes of cellular differentiation almost starts during fetal development when Primordial Germ Cells (PGCs) migrates to germinal ridge to the site of developing gonads, further differentiate into pro-spermatogonia or gonocytes and remain inactive in mitotic state until birth, finally their proliferative activity is resumed around postnatal period and give rise to Spermatogonial Stem Cells
(SSCs) [2]. Next, SSCs restore their proliferative activity around puberty by endocrinal and local signaling stimulation to homeostasis its own appropriate population and differentiation into adequate numbers of progenitor spermatogonia for subsequent spermatogenesis [3-5]. For the maintenance the pool and continuous spermatogenesis, SSCs are divided into two types, type 1 undifferentiated spermatogonia which splits into A-single (As), A-paired (Apr) and A-aligned (Aal) in mice, and A Dark (Ad) and A Pale (Ap) in human. In both species Ap and Aal go further differentiated into A1-A4, intermediate and type $\mathrm{B}$ and get enter into 
meiosis-I to give rise primary spermatocytes, detail described by [4]. Next, meiosis-II gives secondary spermatocytes which further undergo chromatid segregation to generate round spermatids and followed the spermiogenesis to generate spermatozoa where histone replacing and compaction of the chromatin occurs [6]. Finally, the maturation and storage of spermatozoa occur inside epididymis [7].

Spermatogenic arrest could be define as an interruption of the complex process at any stage such as proliferation and differentiation of SSCs, spermatogonia, spermatocytes and spermatids, which may lead to the apoptosis of germ cells [8-10]. Especially the spermatogenic arrest could occurred at the meiotic stages (check points of pachytene spermatocytes and spermiogenesis) [11, 12]. For example, histone protamines are required in spermiogenesis for tight chromatin compaction, because this stage is transcriptionally inert, suggesting the importance of transcriptional regulation for gene expression [13]. Spermatogenic arrest can be cause by genetics, epigenetics, or acquired factors [11], the condition could either be Non-Obstructive Azoospermia (NOA) or Obstructive Azoospermia (OA) $[14,15]$. A short while ago, a several reviews have declared that the miRNA plays a significant role in mammalian spermatogenesis [16-18]. Taken together with previous author's appreciation, this review has also summarized the recent research progress about the role of miRNA during spermatogenesis via regulating candidate genes expression, which may provide insight the molecular mechanism to understand the male infertility.

\section{MicroRNA}

The non-coding small RNA molecules contained $\sim 22$ nucleotides known as miRNAs. This class of small RNAs are mostly found in animals, plants as well as in some viruses $[19,20]$. The first miRNA was discovered 23 years ago by Ambrose's and Ruvkun's with joint research work in
1993, scientists have isolated the gene of small non-coding RNAs, containing a complementary sequence with mRNA in the 3' Un-Translated Region (UTR) of the lin-14 instead of producing encoding protein [21, 22]. After 23 years of miRNA discovery by Lee et al (1993), numerous studies have declared that the miRNAs play a counter role for the expression of the vast array of the protein-coding genes by affecting the stability of mRNA during post-transcription or translation [23, 24]. Studies have also declared that, numerous miRNAs are involved in diverse biological functions including cellular differentiation, apoptosis, proliferation, early embryonic development, and metabolic regulation [2527].

\section{Biogenesis and mechanism of actions of miRNAs}

During past two-decades many studies have revealed that there are thousands of miRNA genes present in mammalian genome within the protein-coding genes regions (intragenic or intergenic). Approximately $60 \%$ of the mammalian genome has predicted to targeted by miRNAs during transcriptional and post-transcriptional phases [28, 29]. For the biogenesis of miRNAs, firstly they are transcribed through RNA polymerase II [30] and hairpin structure is formed which is composed of double-stranded RNA molecules having 100-120 nucleotides called primary miRNA (pri-miRNA). Then RNA-binding protein Drosha (pasha) or "DiGeorge syndrome critical region 8 genes" (DGCR8) are committed to recognize this RNA substrate and function as an endonuclease to help the formation of precursor microRNAs (pre-miRNAs) which is transported to the cytoplasm via protein called as Exportin-5 [31]. Furthermore, after its transportation to cytoplasm the double strand miRNA is processed by another endonuclease, Dicer (RNase III endonuclease), to cut the terminal loop to generate an intermediate 21-22 nucleotide miRNA duplex. One strand of this miRNA duplex subsequently 
binds with Argonaute (AGO) as well as other accessory proteins to build the RNAinduced silencing complex (RISC) [32, 33]. Finally, single stranded microRNAs with specific sequence recognize their target on mRNAs that will be either translationally silenced or degraded depending on their complementary sequence (Error! Reference source not found.). Interestingly a single miRNA can target thousands of mRNAs and the targeted messenger RNA allowed multiple binding sites for the different or same miRNAs.
Thus, miRNAs form potent controlling circuits to regulate various physiological processes $[34,35]$. As the sequence of miRNA is complementary to proteincoding genes on mRNA and leads to the genes deregulation in expression patterns, the deregulation of miRNAs can contribute to the obsessive conditions during development, such as cell apoptosis, cancer and aberrant early embryonic development, cellular differentiation, proliferation, and metabolic regularity [19, 35-38].

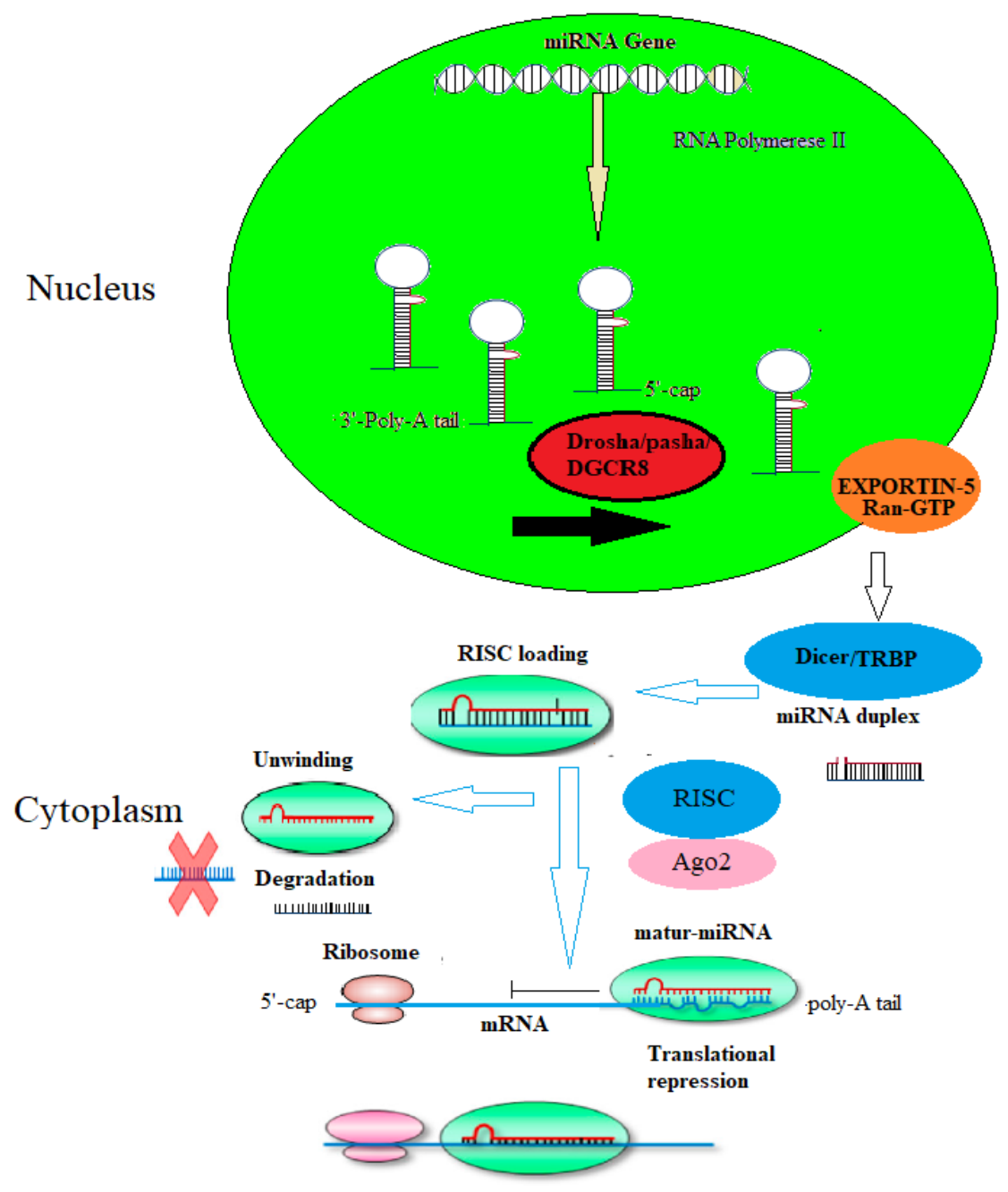

Figure 1. Illustrative diagram of miRNAs biogenesis and mechanism of action

\section{Mammalian spermatogenesis and} microRNA involvement

All phases of spermatogenesis controlled via a number of factors including paracrine regulation, endocrinal control, genetics and epigenetics regulation $[39,40]$ as well as specific genes expression at specific phases. For example, during early phase of 
spermatogenesis synthesized of protamines occurred for later steps [41]. Soumillon et al. (2013) revealed that the miRNAs play critical roles during late spermatogenesis especially at meiosis of spermatocytes and spermiogenesis of spermatids because the testis of mammals have mainly complex transcriptome as compared to all others tissues. In meiotic phase not only proteincoding mRNAs are expressed but also some amount of diverse non-coding RNAs that are derived mostly from uncharacterized (intragenic or intergenic) regions during this phase [42]. To support this assertion many studies have uncovered Differentially Expressed (DE) miRNAs and reported that these small non coding RNA molecules have valuable role in regulation of spermatogenesis of rodent, humans and porcine $[17,43,44]$ (Table 1). There is huge numbers of different RNA proteins of testis-specific in meiotic and post-meiotic phases phase of spermatogenesis of mammals which revealed that for continuous sperm production miRNAs play an essential role in entire process of spermatogenesis $[45,46]$.

\section{MicroRNAs and regulation of PGCs in mammals}

In males, spermatogenesis almost start from developmental process of fetus when the PGCs migrate to genital ridge or allantois to differentiate into pro-spermatogonia or gonocytes which give rise to SSCs, because this initial phase requires a unique geneexpression in PGCs to set aside from somatic cells. The previous studies have also shown the involvement of some miRNAs in the regulation of PGCs. The miR-290-295 and miR-17-92 cluster are reported as highly expressed miRNAs in PGCs to promote the cell cycle [47]. The let-7 miRNAs also have a crucial role in the regulation of PGCs and due to their complementary sequences in developing PGCs. Whereas, the function of let-7 family were reported as tumor suppressors through suppression of Ras protein (core kinase) in Mitogen Activated Protein Kinase (MAPK) pathway when compared to miR-17-92 cluster [48]. Additionally, 6 members of miR-17-92 cluster "miR-17, miR-18a, miR-19a, miR-19b-1, miR-20a and miR92a" play important roles in the PGCs regulation [49]. According to Hayashi et al., (2008) the miR-290 and -295 clusters expression were significantly increased in male PGCs and spermatogonia, interestingly the experimental results of said cluster in dicer knockdown mice had poor proliferation in PGC cells as compared to spermatogonia [50]. Moreover, the let-7 miRNAs (including let-7a, let-7d, let-7e, let-7f, and let-7g) and miR-9 and miR-125a expression level were significantly increased in male PGCs excluding females [48, 51]. In conclusion, the miR-290-295 and miR-17-92 clusters and let-7 family expression were considered as very imperative for regulation of PGCs.

MicroRNAs and spermatogonial stem cells

The non-stop sperm production is dependent on the self-renewal of SSCs to maintain the appropriate pool and continuous differentiation to an adequate number of spermatogonia for subsequent spermatogenesis. In mice and human, SSCs self-renewal is stimulated by Glial cell lineDerived Neurotrophic Factor (GDNF) through the sertoli cells, and Fibroblast Growth Factor 2 (FGF2) is expressed in Leydig cells which interacts with GDNF to enhance proliferation rate of SSCs [39]. According to previous reports, around $50 \%$ of the SSCs populations endured selfrenewal through GDNF, whereas reaming $50 \%$ will further differentiate into spermatogonia to continue production of spermatozoa through FGF2 and GDNF interaction [52, 53]. In addition the controlling of the endocrine and local signaling system, some miRNAs are also involved in regulation and differentiation of SSCs via targeting the candidate genes. According to earlier reports, there are different miRNAs have key role in homeostasis of SSCs. Such as global expression of miRNAs in mice's testis Thy1+ and Thy1-cell population showed 
miR-34c, miR-146a, miR-182, miR-183 along with miR-21 were highly expressed in an enriched population of Thy1+ SSCs as compared with Thy1-somatic cells. Additionally in SSCs-enriched germ cells miR-21 could induce apoptosis and cell numbers were significantly decreased indicating its importance in the maintenance of SSCs population regulated by the transcription factor ETV5 [54]. The High expression of miR-10b leads to enhanced proliferation of mouse SSCs by targeting the member of KLF family of transcription factors (KLF4), one of the most important induced pluripotent stem factors causing stagnation of the cell cycle at $\mathrm{G} 1 / \mathrm{S}$ and $\mathrm{G} 2 / \mathrm{M}$ phases, while knockdown of miR-10b significantly increased the apoptosis of SSCs [55]. Another miRNA, the miR-34c expression was analyzed in caprine male germ line stem cells and it has been reported that the overexpression of this miRNA promoted apoptosis and suppressed proliferation with p53 dependent pathway [56]. While, miR$34 \mathrm{c}$ also targeted the Nanos 2 which belongs to Nanos family protein and plays a key role in spermatogonial stem cell regulation [57]. Moreover, the miR-106a and miR-20 have also been reported as differentially expressed in SSCs which was essential for the self-renewal via targeting Ccnd1 and Stat3 genes [58]. In addition, Doublesex and Mab-3-related transcription factor1 (DMRT1) gene was a dose-sensitive transcription factor essential for regulation of Sertoli cells and germ cell in mammalian testis. The functional analysis of miR-224 was carried out by using mimics and inhibitors, which revealed that miR-224 was crucial for the SSCs differentiation and it has been reported that miRNA 224 targets DMRT1 and mediates the SSCs self-renewal by $\mathrm{WNT} / \beta$-catenin signaling pathway [59]. The miR-34c-3p was able to down regulate the expression of Phosphatidylinositol Specific Phospholipase C-X Domain Containing 3 (PLCXD3) which mediates the several physiological actions such as growth factors, hormones, neurotransmitters in Murinae and Homo sapiens cell lines [60]. A recent study reported that miR-184 is involved in targeting NCOR2 on 3'-UTR which is important for the regulation of germ cell line [61]. The DE miRNAs profiling were investigated in human azoospermia patients, which was also suggesting that miR-184 is involved in the homeostasis of SSCs via targeting the E2F Transcription Factor 1 (E2F1) [17]. Whereas, E2F1 was responsive to miR-383 in mouse spermatogenesis [62]. Taken together all above discussed miRNAs have been considered as very important in the regulation of SSCs differentiation and selfrenewal.

\section{MicroRNAs and differentiation of spermatogonia}

In this phase SSCs are divided into undifferentiated and differentiated spermatogonia to maintain the pool of SSCs and consequent production primary spermatocytes for subsequent spermatogenesis [4]. According to previous studies, the Retinoic acid (RA) signaling is necessary for spermatogonial differentiation and maintain the pool SSCs by controlling the genes expression [63]. The expression of miR-17-92 and miR106b-25 were significantly down-regulated in the RA-induced exposure during the differentiation of spermatogonia and expression of Bim, Kit, Socs3, and Stat3 genes were up-regulated, in the result of knockout miR-17-92 mice exhibited a few spermatozoa in the epididymis with small testes $[49,64]$. Whereas, the miR-146 was highly expressed in spermatogonia at undifferentiated state but transcriptional level got diminish up to 180-fold at differentiated state; so it was an assumption that the RA induced by miR-146 during differentiation spermatogonia in rodents [65]. Apart from above discussed miRNAs, some other miRNAs were also been reported as involved in the regulation of spermatogonia at undifferentiated stage. For instance, high expression of clustered miR-221 and miR-222 caused the down- 
regulation of RA in undifferentiated cells, for example impaired miR-221 and miR222 caused loss in stem cell capacity and induced cellular differentiation through the repression of KIT [66]. Additionally, the LIN28 was considered as regulator of the self-renewal of germ line stem cells and regulate the cyclic expansion of spermatogonial progenitor population of undifferentiated spermatogonia, the miRlet-7 family showed a conflict expression pattern by induction of RA stimulation along with down-regulation of targets genes (Mycn, Ccnd1, and Colla2) whereas after RA treatment the expression level of the let-7 families members were simultaneously decreased $[64,67]$. It was understood that, to maintain the state of undifferentiated spermatogonia and SSCs pool the expression of genes not only controlled by RA but some miRNAs are also involved.

In recent times, Liu et al., (2015) reported 173 DE miRNAs between spermatogonia and spermatocytes, in which members of miR-125 family and let-7 family were suggested that these miRNAs families are important for promoting the differentiation (Table 1) [17]. According to deep sequencing of spermatogenic cell of NOA compared with OA by Yao et al., (2017) suggested that, the miR-143-3p, miR-1005p, miR-99a-5p, miR-99b-5p, and -miR$145-5 p$ were significantly up regulated in spermatogonia of NOA humans when compared to OA. While, miR-105-5p, miR296-5p and miR-373-3p were reported as down regulated in spermatogonia of NOA compared with OA [68], All taken together these DE miRNAs suggesting the valuable role in the maintenance and differentiation of spermatogonia.

\section{MicroRNAs and meiosis of spermatocytes}

Meiosis is a complicated phase in spermatogenesis, particularly in meiotic stages of leptotene/zygotene are mostly transcriptionally inert to the posttranscriptional regulation in gene expression $[69,70]$, because testis having high complex transcriptome as compared with other tissue, especially the origination of high transcriptional activity at stage of pachytene spermatocytes, which known as check point of spermatogenesis [42]. It must be carefully regulated however any mistake in this process leads to spermatogenic arrest. According to previous reports, there are distinct miRNAs play a crucial function for cell division in later steps of spermatogenesis including meiosis of spermatocytes and spermiogenesis [72, 73]. It was reported that miRNA mediated meiotic and postmeiotic phases of spermatogenesis, which was proved by an experimental study about dicer1 knockout phenotype [40]. The miR$34 \mathrm{c}$ has been suggested as a significant miRNA in SSCs [57]. Conversely, in primary spermatocytes miR-34c expression is similarly important such as downregulation of miR-34c leaded to prevention of germ cells from $\mathrm{T}$ deprivation-induced apoptosis, on the other hand, the overexpression of $\mathrm{miR}-34 \mathrm{c}$ triggered apoptosis by targeting on 3'-UTR of activating transcription factor 1 (ATF1) [71, 72, 73]. Moreover upon the initiation of meiosis, the miR-449 cluster and miR$34 \mathrm{~b} / \mathrm{c}$ functioned redundantly in downregulating the activities of the E2F-pRb pathway in murine testes $[74,75]$.

Additionally, it was reported that Protamine (Prm) is required for successful compaction of the sperm chromatin by replacing histone, these Prm mRNAs have already been synthesized and expression of these Prm dependent on the accurate time during late spermatogenesis $[76,77]$. To prove this exactly timed expression, the miRNA mediated mechanisms for Transition Proteins (TPs) and Prms were subjected to a broad post-transcriptional mechanism, Tp2 and Prm 2 been shown to targeted by miR-469 which led the repression of their expression at translation level in spermatocytes and spermatids with a negligible effect on mRNA deprivation. Interestingly, in contrast of miR-469 the miR-122a also can bind with Tp2 on 3'- 
UTR which induced mRNA cleavage and lead to the abnormal spermatozoa in experimental mice [78]. Furthermore, Fatime et al., (2014) has investigated that the following miRNAs (including miR-34a, $-181 b,-469$ and -122a) altering their expression level by exposure of tertiarybutyl hydroperoxide (TBHP) and suggested that are these miRNAs were involved in cellular functions including cell cycle and apoptosis [79], moreover consistency in the expression level about said miRNAs has been found in previous studies [16, 79]. Recently, Liu et al., (2015) reported 173 DE miRNAs profile between spermatocytes and spermatids in human azoospermic patients, among those miR-34b-5p and miR-34c-5p were significantly upregulated in spermatocytes as compared with round spermatids and it was suggested that these miRNAs are critical at meiosis phase of spermatocytes [17]. Moreover, according to Yao et a., (2017) the expression levels of following miRNAs including "miR-181a-5p, miR-423-5p, miR-26a-5p, miR-140-3p, miR-21-5p, miR-424, miR-186-5p, Let-7e-5p, Let-7b, and miR-374b" were significantly up regulated in spermatocytes of NOA when compared with OA patients. Contrariwise, the hsa-miR-31-5p were down regulated in spermatocytes of NOA when compared with OA [68]. All above findings revealed the valuable role of miRNAs in the proliferation of spermatocytes to spermatids.

\section{MicroRNAs and spermiogenesis}

Spermiogenesis known as for differentiation of the spermatid into the spermatozoa by their morphological changes such as condensation of genetic material and nucleus, loss of cytoplasm, formation of the acrosome and axoneme. The role miRNAs in this step is epigenetics controle because sperm not only carries the genome also carry epigenome in form of DNA methylation, histone retained and small noncoding RNA. The miR-34b/c or miR-449 were reported as essential for normal fertilization whereas deficiency of these miRNAs impaired both meiosis and the final stages of spermatozoa maturation in rodents and pigs $[75,80,81]$. Additionally, higher expression let-7 families (let-7a, let $-7 \mathrm{~d}$ and let -7e) and miR-22 can alter the expression of their corresponding targeted genes (HMGA2, 809, ODF1 and 4956) those coded proteins involved in spermatogenesis, metabolism of sperm structure and motility and led the abnormal sperm in semen of boars [82]. Based on in-silico method several miRNAs in various swine breeds Yorkshire, Landrace, and Duroc, were investigated which revealed that seventeen miRNAs (miR-514a-3p, -196a-5p, -372-3p, -938, 558, -579-3p, -648, -524-3p, -595, -512-3p, $-639,-551 \mathrm{a},-429,-624-5 \mathrm{p},-585-3 \mathrm{p},-508-$ $3 p$ and -626) were significantly down regulated in the spermatozoa of Yorkshire and Landrace compared to Duroc, which suggested these miRNAs are very essential final stage of spermatogenesis [83]. Moreover, the DE miRNAs (has-aga-3155, has-aga-8197, has-aga-6727, has-aga11796, has-aga-14189, has-aga-6125 and has-aga-13659) were identified in spermatozoa of bulls with high fertility when compared low fertile bulls, and these DE miRNAs were suggested an important for the regulatory mechanisms of bovine sperm capacitance [84]. While, a study on human regarding seminal plasma of idiopathic infertile and fertile males was suggested that the expression of miRNAs (mir-146a, mir-196a-2, and mir-499) were important for cellular proliferation, apoptosis and maintenance of cell cycle [85]. Moreover DE miRNAs profiling NOA patients compared with OA patients suggested that the expression levels of miR10b-5p, miR-409-5p, miR-199b-3p, Let7g-5p, miR-127-3p, miR-221-3p, Let-7i-5p, Let-7f-5p, and miR-145-3p were significantly up regulated, whereas miR-9$3 p$ was down regulated in round spermatids [68]. 
Table. 1. Involvement of miRNA during spermatogenesis in mammals

\begin{tabular}{|c|c|c|}
\hline MicroRNAs & $\begin{array}{c}\text { Involvement and regulation stages } \\
\text { during spermatogenesis }\end{array}$ & References \\
\hline $\begin{array}{ll}\text { - } & \text { miR-17-92 and miR-290-295 } \\
\text { - } & \text { miR- let-7 faimly } \\
\text { - } & \text { miR-9 and miR-125a }\end{array}$ & $\begin{array}{l}\text { PGCs (primordial germ cells) } \\
\text { regulation }\end{array}$ & $\begin{array}{l}{[47]} \\
{[48]} \\
{[51]}\end{array}$ \\
\hline $\begin{array}{ll}\text { - } & \text { miR-34c, miR-146a, miR-182, } \\
& \text { miR, } 183 \text { and miR -21 } \\
\text { - } & \text { miR-10b } \\
\text { - } & \text { miR-106a and miR-20 } \\
\text { - } & \text { miRNA-224 } \\
\text { - } & \text { miR-34c-3p } \\
\text { - } & \text { miR-383 }\end{array}$ & $\begin{array}{l}\text { SSCs (spermatogonial stem cells) self- } \\
\text { renewal and differentiation }\end{array}$ & $\begin{array}{l}54] \\
{[55]} \\
{[58]} \\
{[59]} \\
{[60]} \\
{[61]} \\
{[62]}\end{array}$ \\
\hline $\begin{array}{ll} & \text { miR-106b-25 and miR-17-92 } \\
\text { - } & \text { miR-146 } \\
\text { - } & \text { miR-221 and miR-222 } \\
\text { - } & \text { miR-let-7 } \\
\text { and miR-125 family (miR-125b-1-3p } & \text { (e.g., let-7a-5p, let-7b-5p, let-7c } \\
\text { let-7d-5p, 7e-5p, let-7f-5p and let- } \\
\text { 7g-5p) } \\
\text { miR-100-5p,miR-143-3p, miR- } \\
\text { 99a-5p, miR-99b-5p, -miR-145-5p } \\
\text { and miR-373-3p, miR-105-5p, and } \\
\text { miR-296-5p }\end{array}$ & $\begin{array}{l}\text { Mitotic differentiation of } \\
\text { spermatogonia }\end{array}$ & $\begin{array}{c}{[49,64]} \\
{[65]} \\
{[66]} \\
{[64,67]} \\
{[17]} \\
{[68]}\end{array}$ \\
\hline $\begin{array}{ll} & \mathrm{miR}-34 \mathrm{c} \\
\text { - } & \mathrm{miR}-449 \text { and miR-34b/c } \\
\text { miR-469 miR-122a, miR-34a, and } \\
\text { miR-181b } \\
\text { miR-34b-5p and miR-34c-5p } \\
\text { miR-181a-5p, miR-423-5p, miR- } \\
\text { 26a-5p, miR-140-3p, miR-21-5p, } \\
\text { miR-424, miR-186-5p, Let-7e-5p, } \\
\text { Let-7b, miR-374b, and miR-31-5p }\end{array}$ & Meiotic proliferation of spermatocytes & $\begin{array}{c}{[72,74]} \\
{[75]} \\
{[16,79]} \\
\\
{[17]} \\
{[68]}\end{array}$ \\
\hline $\begin{array}{ll} & \text { miR-34b/c and miR-449 } \\
\text { - } & \text { miR-let-7 family } \\
& \text { miRNAs }(-514 a-3 p,-196 a-5 p,- \\
& \text {-524-3p, -938, -558, -579-3p, -648, } \\
& \text { 551a, -429, -624-5p, -585-3p, - } \\
& \text { 508-3p and -626) } \\
\text { - } & \text { miRNAs (has-aga-3155, has-aga- } \\
& \text { 8197, has-aga-6727, has-aga- } \\
& \text { 11796, has-aga-14189, has-aga- } \\
& \text { 6125 and has-aga-13659) } \\
\text { - } & \text { mir-146a, mir-196a-2, and mir-499 } \\
\text { miR-10b-5p, miR-409-5p, miR- } \\
\text { 199b-3p, Let- 7g-5p, miR-127-3p, } \\
\text { miR-221-3p, Let-7i-5p, Let-7f-5p, } \\
\text { miR-145-3p, and miR-9-3p. }\end{array}$ & Spermiogenesis & $\begin{array}{c}{[\mathbf{8 0}, \mathbf{8 1}]} \\
{[\mathbf{8 2}]} \\
{[83]}\end{array}$ \\
\hline
\end{tabular}




\section{Conclusion}

In conclusion, numerous researches have declared that miRNA are involved in mammalian spermatogenesis, including mitosis, meiosis and spermiogenesis stages, so it has been become very clear that miRNAs play a significant role in the regulation of the vast array of organized gene expression profiles at posttranscription and translation stages throughout the spermatogenesis. The identified miRNA may represent a potentially novel regulatory network for understanding molecular mechanism of spermatogenesis dysfunction. Although some miRNA regulatory function has been determined, whereas the most miRNAs function is not yet clear. All previous studies about DE miRNAs showed the particular miRNAs and their targeted genes but the most of miRNAs and their corresponding targeted genes need functional analysis by using miRNAs mimic and inhibitors. In addition, almost miRNAs research have been conducted on rodent models and some of them focused on spermatogenic cells of humans and domestic animals. Further research about spermatogenic disorder can be conducted through germ line stem cells culture to elucidate specific miRNAs involved in male infertility which could help to create a view about the requirements of normal fertility of male.

\section{Authors' contributions}

Conceived and designed the study: C Xin, MA Shah \& $\mathrm{C} \mathrm{Xu}$, Contributed to revise the manuscript: S Wu, C Yi, Kifayatullah \& A Baber, Wrote the paper: C Xin, MA Shah \& $\mathrm{C} \mathrm{Xu}$.

\section{Acknowledgement}

This work was supported by the grants from the National Natural Science Foundation of China (31572396) and Longshan Academic Talent Research Supporting Program of SWUST (17LZX515). We apologize to those whose works are not cited here due to space limitation and repetition. We acknowledge to Assoc. Prof. Rehana Shahnawaz for her kind help in English language revision.

\section{References}

1. Jan SZ, Hamer G, Repping S, de Rooij DG, Van Pelt AMM \& Vormer TL (2012). Molecular control of rodent spermatogenesis. Biochimica et Biophysica Acta - Molecular Basis of Disease 1822: 1838-1850.

2. Clermont Y \& Perey B (1957). Quantitative study of the cell population of the seminiferous tubules in immature rats. Am $J$ Anat 100: 241-267.

3. Hofmann M-C (2008). Gdnf signaling pathways within the mammalian spermatogonial stem cell niche. Mol Cell Endocrinol 288: 95-103.

4. Kanatsu-Shinohara $M$ \& Shinohara $T$ (2013). Spermatogonial Stem Cell SelfRenewal and Development. Annu. Rev. Cell Dev. Biol. 29; 163-187.

5. Shenghui H, Nakada D \& Morrison SJ (2009). Mechanisms of Stem Cell SelfRenewal. Annu Rev Cell Dev Biol 25: 377406.

6. Rathke C, Baarends WM, Awe S \& Renkawitz-Pohl R (2014). Chromatin dynamics during spermiogenesis. Biochimica et Biophysica Acta - Gene Regulatory Mechanisms 1839: 155-168.

7. Guyonnet B, Dacheux F, Dacheux J-L \& Gatti J-L (2011). The Epididymal Transcriptome and Proteome Provide Some Insights Into New Epididymal Regulations. J Androl 32: 651-664.

8. Bolor $\mathrm{H}$, Zhao WD, Ishikawa $\mathrm{A} \&$ and Wakasugi N (2005). Arrest of spermatogenesis at the early meiotic stage in the small testis mutant (Smt) mice. Exp Anim 54: 327-337.

9. Papanicolaou A, Papadimas J, Nenopoulou H, Zeginiadou T \& Mantalenakis S (2001). Can maturation arrest occur at the stage of spermiogenesis? Syst Biol Reprod Med 46: 105-107.

10. Cai X, Yu S, Mipam TD, Yang F, Zhao W, Liu W, Cao SZ, Shen L, Zhao F, Sun L, Xu C \& Wu S (2017). Comparative analysis of testis transcriptomes associated with male infertility in cattleyak. Theriogenology 88 : 28-42.

11. Málaga Correa YR, Ortiz Núñez DA, Hernández Marín I, Tovar JM \& Ayala Ruíz A (2005). Detención de la espermatogénesis. Ginecol Obstet Mex 73: 500-508.

12. Martin-du Pan RC \& Campana A (1993). 
Physiopathology of spermatogenic arrest. Fertil Steril 60: 937-946.

13. Kotaja N, Bhattacharyya SN, Jaskiewicz L, Kimmins S, Parvinen M, Filipowicz W \& Sassone-Corsi P (2006). The chromatoid body of male germ cells: similarity with processing bodies and presence of Dicer and microRNA pathway components. Proc Natl Acad Sci USA. 103: 2647-52.

14. Hu Z, Xia Y, Guo X, Dai J, Li H, Hu H, Jiang Y, Lu F, Wu Y, Yang X, Li H, Yao B, Lu C, Xiong C, Li Z, Gui Y, Liu J, Zhou Z, Shen H, Wang $X$ \& Sha J (2011). A genome-wide association study in Chinese men identifies three risk loci for nonobstructive azoospermia. Nat Genet 44: 183-186.

15. Tu W, Liu Y, Shen Y, Yan Y, Wang X, Yang D, Li L, Ma Y, Tao D, Zhang S \& Yang Y (2015). Genome-Wide Loci Linked to Non-Obstructive Azoospermia Susceptibility May Be Independent of Reduced Sperm Production in Males with Normozoospermia1. Biol Reprod 92.

16. Dai L, Tsai-Morris C-HH, Sato H, Villar J, Kang J-HH, Zhang J \& Dufau ML (2011). Testis-specific miRNA-469 up-regulated in gonadotropin-regulated testicular RNA helicase (GRTH/DDX25)-null mice silences transition protein 2 and protamine 2 messages at sites within coding region: Implications of its role in germ cell development. J Biol Chem 286: 4430644318.

17. Liu Y, Niu M, Yao C, Hai Y, Yuan Q, Liu Y, Guo Y, Li Z \& He Z (2015). Fractionation of human spermatogenic cells using STA-PUT gravity sedimentation and their miRNA profiling. Sci Rep 5: 8084.

18. Zhang S, Yu M, Liu C, Wang L, Hu Y, Bai Y \& Hua J (2012). MIR-34c regulates mouse embryonic stem cells differentiation into male germ-like cells through RARg. Cell Biochem Funct 30: 623-632.

19. AMBROS V (2003). A uniform system for microRNA annotation. RNA. 9: 277-279.

20. Jones-Rhoades MW \& Bartel DP (2004). Computational identification of plant MicroRNAs and their targets, including a stress-induced miRNA. Mol Cell 14: 787799.

21. Lee RC, Feinbaum RL \& Ambros V (1993). The C. elegans heterochronic gene lin-4 encodes small RNAs with antisense complementarity to lin-14. Cell 75: $843-$ 854.

22. Wightman B, Ha I \& Ruvkun G (1993). Posttranscriptional regulation of the heterochronic gene lin-14 by lin-4 mediates temporal pattern formation in C. elegans. Cell 75: 855-862.

23. Bartel DP (2009). MicroRNAs: Target Recognition and Regulatory Functions. Cell 136: 215-233.

24. Ghildiyal M \& Zamore PD (2009). Small silencing RNAs: an expanding universe. Nat Rev Genet 10: 94-108.

25. Song L \& Tuan RS (2006). MicroRNAs and cell differentiation in mammalian development. Birth Defects Research Part C-Embryo Today: Reviews 78: 140-149.

26. Pogue AI, Cui JG, Li YY, Zhao Y, Culicchia F \& Lukiw WJ (2010). Micro RNA-125b (miRNA-125b) function in astrogliosis and glial cell proliferation. Neurosci Lett 476: 18-22.

27. Xiao C \& Rajewsky K (2009). MicroRNA Control in the Immune System: Basic Principles. Cell 136: 26-36.

28. Castellano L \& Stebbing J (2013). Deep sequencing of small RNAs identifies canonical and non-canonical miRNA and endogenous siRNAs in mammalian somatic tissues. Nucleic Acids Res. 41: 3339-3351.

29. Friedman RC, Farh KKH, Burge CB \& Bartel DP (2009). Most mammalian mRNAs are conserved targets of microRNAs. Genome Res 19: 92-105.

30. Lee Y, Kim M, Han J, Yeom K-H, Lee S, Baek SH \& Kim VN (2004). MicroRNA genes are transcribed by RNA polymerase II. The EMBO Journal 23: 4051-4060.

31. Krol J, Loedige I \& Filipowicz W (2010). The widespread regulation of microRNA biogenesis, function and decay. Nat. Rev. Genet. 11; 597-610.

32. Pratt AJ \& MacRae IJ (2009). The RNAinduced silencing complex: A versatile gene-silencing machine. J Biol Chem. 284: 17897-17901.

33. Redfern AD, Colley SM, Beveridge DJ, Ikeda N, Epis MR, Li X, Foulds CE, Stuart LM, Barker A, Russell VJ, Ramsay K, Kobelke SJ, Li X, Hatchell EC, Payne C, Giles KM, Messineo A, Gatignol A, Lanz RB, O’Malley BW \& Leedman PJ (2013). RNA-induced silencing complex (RISC) Proteins PACT, TRBP, and Dicer are SRA 
binding nuclear receptor coregulators. Proc Natl Acad Sci 110: 6536-6541.

34. Sood P, Krek A, Zavolan M, Macino G \& Rajewsky N (2006). Cell-type-specific signatures of microRNAs on target mRNA expression. Proc Natl Acad Sci USA. 103: 2746-51.

35. Huntzinger E \& Izaurralde E (2011). Gene silencing by microRNAs: contributions of translational repression and mRNA decay. Nat Rev Genet 12: 99-110.

36. Lewis BP, Shih I-H, Jones-Rhoades MW \& Bartel DP (2003). Prediction of Mammalian MicroRNA Targets that they could have many more regulatory functions than those uncovered to date LagosQuintana et al. Cell 115: 787-798.

37. Thomson JM, Newman M, Parker JS, Morin-Kensicki EM, Wright $\mathrm{T}$ \& Hammond SM (2006). Extensive posttranscriptional regulation of microRNAs and its implications for cancer. Genes Dev 20: 2202-2207.

38. Wang Z, Yao H, Lin S, Zhu X, Shen Z, Lu G, Poon WS, Xie D, Lin MCM \& Kung HF (2013). Transcriptional and epigenetic regulation of human microRNAs. Cancer Lett.331; 1-10.

39. Phillips BT, Gassei K \& Orwig KE (2010). Spermatogonial stem cell regulation and spermatogenesis. Philosophical transactions of the Royal Society of London Series B, Biological sciences 365: $1663-$ 1678.

40. Yao C, Liu Y, Sun M, Niu M, Yuan Q, Hai Y, Guo Y, Chen Z, Hou J, Liu Y \& He Z (2015). MicroRNAs and DNA methylation as epigenetic regulators of mitosis, meiosis and spermiogenesis. Reproduction 150: 25-34.

41. Kimmins S, Kotaja N, Davidson I \& Sassone-Corsi P (2004). Testis-specific transcription mechanisms promoting male germ-cell differentiation. Reproduction 128: 5-12.

42. Soumillon M, Necsulea A, Weier M, Brawand D, Zhang X, Gu H, Barthès P, Kokkinaki M, Nef S, Gnirke A, Dym M, deMassy B, Mikkelsen TS \& Kaessmann H (2013). Cellular Source and Mechanisms of High Transcriptome Complexity in the Mammalian Testis. Cell Rep 3: 2179-2190.

43. Chen X, Che D, Zhang P, Li X, Yuan Q, Liu T, Guo J, Feng T, Wu L, Liao M, He Z \& Zeng W (2017). Profiling of miRNAs in porcine germ cells during spermatogenesis. Reproduction 154: 789-798.

44. Luo MM, Hao LL, Hu F, Dong YN, Gou LX, Zhang WD, Wang X, Zhao YH, Jia MC, Hu SN \& Zhang XJ (2015). MicroRNA profiles and potential regulatory pattern during the early stage of spermatogenesis in mice. Sci China Life Sci 58: 442-450.

45. Paronetto MP \& Sette C (2010). Role of RNA-binding proteins in mammalian spermatogenesis. Int J Androl 33: 2-12.

46. Idler RK \& Yan W (2012). Control of Messenger RNA Fate by RNA-Binding Proteins: An Emphasis on Mammalian Spermatogenesis. J Androl 33: 309-337.

47. Hayashi K, Chuva de Sousa Lopes SM, Kaneda M, Tang F, Hajkova P, Lao K, O'Carroll D, Das PP, Tarakhovsky A, Miska EA, Surani MA, Chuva SM, Lopes DS, Kaneda M, Tang F, Lao K, Carroll DO, Das PP, Tarakhovsky A, Miska EA \& Azim $M$ (2008). MicroRNA biogenesis is required for mouse primordial germ cell development and spermatogenesis. PLoS One 3: 1-9.

48. Takamizawa J, Konishi H, Yanagisawa K, Tomida S, Osada H, Endoh H, Harano T, Yatabe Y, Nagino M, Nimura $Y$, Mitsudomi T \& Takahashi T (2004). Advances in Brief Reduced Expression of the let-7 MicroRNAs in Human Lung Cancers in Association with Shortened Postoperative Survival. Cancer Res 64 (11): 3753-6.

49. Xie R, Lin X, Du T, Xu K, Shen H, Wei F, Hao W, Lin T, Lin X, Qin Y, Wang H, Chen L, Yang S, Yang J, Rong X, Yao K, Xiao D, Jia J \& Sun Y (2016). Targeted Disruption of miR-17-92 Impairs Mouse Spermatogenesis by Activating mTOR Signaling Pathway. Medicine 95: e2713.

50. Hayashi K, Chuva SM, Lopes DS, Kaneda M, Tang F, Lao K, Carroll DO, Das PP, Tarakhovsky A, Miska EA \& Azim M (2008). MicroRNA Biogenesis Is Required for Mouse Primordial Germ Cell Development and Spermatogenesis. PLoS One 3: 1-9.

51. Johnson SM, Grosshans H, Shingara J, Byrom M, Jarvis R, Cheng A, Labourier E, Reinert KL, Brown D, Slack FJ \& Haven N (2005). RAS Is Regulated by the let-7 MicroRNA Family. Cell 120: 635-647.

52. Kubota H, Avarbock MR \& Brinster RL 
(2004). Growth factors essential for selfrenewal and expansion of mouse spermatogonial stem cells. Proc Natl Acad Sci 101: 16489-16494.

53. Takashima S, Kanatsu-Shinohara M, Tanaka T, Morimoto H, Inoue K, Ogonuki N, Jijiwa M, Takahashi M, Ogura A \& Shinohara T (2015). Functional differences between GDNF-dependent and FGF2dependent mouse spermatogonial stem cell self-renewal. Stem Cell Reports 4: 489-502.

54. Niu Z, Goodyear SM, Rao S, Wu X, Tobias JW, Avarbock MR \& Brinster RL (2011). MicroRNA-21 regulates the self-renewal of mouse spermatogonial stem cells. Proc Natl Acad Sci USA 108: 12740-12745.

55. Li J, Liu X, Hu X, Tian GG, Ma W, Pei X, Wang Y \& Wu J (2017). MicroRNA-10b regulates the renewal of spermatogonial stem cells through Kruppel-like factor 4 . Cell Biochem Funct. 35: 184-191.

56. Li M, Yu M, Liu C, Zhu H, He X, Peng S \& Hua J (2013). miR-34c works downstream of p53 leading to dairy goat male germline stem-cell (mGSCs) apoptosis. Cell Prolif 46: 223-231.

57. Yu M, Mu H, Niu Z, Chu Z, Zhu H \& Hua J (2014). Mir-34c enhances mouse spermatogonial stem cells differentiation by targeting Nanos2. J Cell Biochem 115: 232-242.

58. He Z, Jiang J, Kokkinaki M, Tang L, Zeng W, Gallicano I, Dobrinski I \& Dym M (2013). MiRNA-20 and MiRNA-106a Regulate Spermatogonial Stem Cell Renewal at the Post-Transcriptional Level via Targeting STAT3 and Cond1. Stem Cells 31: 2205-2217.

59. Cui N, Hao G, Zhao Z, Wang F, Cao J \& Yang A (2016). MicroRNA-224 regulates self-renewal of mouse spermatogonial stem cells via targeting DMRT1. J Cell Mol Med 20: $1503-1512$.

60. Li Z, Zheng Z, Ruan J, Li Z, Zhuang X \& Tzeng C-M (2016). Integrated analysis miRNA and mRNA profiling in patients with severe oligozoospermia reveals miR34c-3p downregulates PLCXD3 expression. Oncotarget 7(33): 52781-52796

61. Wu J, Bao J, Wang L, Hu Y, Xu C, Braun R, Bartel D, Ro S, Park C, Sanders K, McCarrey J, Yan W, Yan N, Lu Y, Sun H, Tao D, Zhang S, Liu W, Ma Y, Hayashi K, Lopes SC de S, Kaneda M \& Kauppinen S (2011). MicroRNA-184 downregulates nuclear receptor corepressor 2 in mouse spermatogenesis. BMC Dev Biol 11: 64.

62. Tian H, Cao YX, Zhang XS, Liao WP, Yi YH, Lian J, Liu L, Huang HL, Liu WJ, Yin MM, Liang M, Shan G \& Sun F (2013). The targeting and functions of miRNA-383 are mediated by FMRP during spermatogenesis. Cell Death Dis 4. e617.

63. Chen Y, Ma L, Hogarth C, Wei G, Griswold MD \& Tong M-H (2016). Retinoid signaling controls spermatogonial differentiation by regulating expression of replication-dependent core histone genes. Development 143: 1502-1511.

64. Tong M, Mitchell D, Evanoff R \& Griswold MD (2017). Expression of Mirlet7 Family MicroRNAs in Response to Retinoic Acid-Induced Spermatogonial Differentiation in Mice 1 In Situ miRNA Hybridization with Locked Nucleic. 197: 189-197.

65. Huszar JM \& Payne CJ (2013). MicroRNA 146 (Mir146) modulates spermatogonial differentiation by retinoic acid in mice. Biol Reprod 88: 15.

66. Yang Q-E, Racicot KE, Kaucher A V, Oatley MJ \& Oatley JM (2013). MicroRNAs 221 and 222 regulate the undifferentiated state in mammalian male germ cells. Development 140: 280-90.

67. Mayr F \& Heinemann U (2013). Mechanisms of Lin28-mediated miRNA and mRNA regulation--a structural and functional perspective. Int $\mathrm{J} \mathrm{Mol} \mathrm{Sci} \mathrm{14:}$ 16532-16553.

68. Yao C, Yuan Q, Niu M, Fu H, Zhou F, Zhang W, Wang H, Wen L, Wu L, Li Z \& He Z (2017). Distinct expression profiles and novel targets of microRNAs in human spermatogonia, pachytene spermatocytes and round spermatids between OA patients and NOA patients. Mol Ther - Nucleic Acids 9: 182-194.

69. Paronetto MP, Messina V, Barchi M, Geremia R, Richard S \& Sette C (2011). Sam68 marks the transcriptionally active stages of spermatogenesis and modulates alternative splicing in male germ cells. Nucleic Acids Res 39: 4961-4974.

70. Monesi V (1964). Ribonucleic acid synthesis during mitosis and meiosis in the mouse testis. J Cell Biol 22: 521-32.

71. Bouhallier F, Allioli N, Lavial F, Chalmel F, Perrard MH, Durand P, Samarut J, Pain B \& Rouault JP (2010). Role of miR-34c 
microRNA in the late steps of spermatogenesis. RNA 16: 720-731.

72. Adav RP \& Kotaja N (2014). Small RNAs in spermatogenesis. Mol Cell Endocrinol 382: 498-508.

73. Liang X, Zhou D, Wei C, Luo H, Liu J, Fu $\mathrm{R} \&$ Cui S (2012). MicroRNA-34c enhances murine male germ cell apoptosis through targeting ATF1. Plos one 7(3): e33861.

74. Bao J, Li D, Wang L, Wu J, Hu Y, Wang Z, Chen Y, Cao X, Jiang C, Yan W \& Xu C (2012). MicroRNA-449 and MicroRNA$34 \mathrm{~b} / \mathrm{c}$ function redundantly in murine testes by targeting E2F transcription factorretinoblastoma protein $(\mathrm{E} 2 \mathrm{~F}-\mathrm{pRb})$ pathway. J Biol Chem 287: 21686-21698.

75. Yuan S, Tang C, Zhang Y, Wu J, Bao J, Zheng H, Xu C \& Yan W (2015). mir-34b/c and $\mathrm{mir}-449 \mathrm{a} / \mathrm{b} / \mathrm{c}$ are required for spermatogenesis, but not for the first cleavage division in mice. Biol Open 4: 212-223.

76. Meistrich ML, Mohapatra B, Shirley CR \& Zhao M (2003). Roles of transition nuclear proteins in spermiogenesis. Chromosoma 111: 483-488.

77. Zhao M, Shirley CR, Mounsey S \& Meistrich ML (2004). Nucleoprotein transitions during spermiogenesis in mice with transition nuclear protein Tnp1 and Tnp2 mutations. Biol Reprod 71: 1016-25.

78. Yu Z, Raabe $\mathrm{T} \&$ Hecht NB (2005). MicroRNA Mirn122a Reduces Expression of the Posttranscriptionally Regulated Germ Cell Transition Protein 2 (Tnp2) Messenger RNA (mRNA) by mRNA Cleavage1. Biol Reprod 73: 427-433.

79. Fatemi N, Sanati MH, Shamsara M,
Moayer F \& Gourabi H (2014). TBHPinduced oxidative stress alters microRNAs expression in mouse testis. J Assist Reprod Genet 31(10): 1287-1293

80. Comazzetto S, Giacomo M Di, Rasmussen KD, Much C, Azzi C, Carroll O, Perlas E \& Morgan M (2014). Oligoasthenoteratozoospermia and Infertility in Mice Deficient for miR-34b / c and miR-449 Loci. PLoS Genet 10(10): e1004597.

81. Jodar M, Selvaraju S, Sendler E, Diamond MP \& Krawetz SA (2013). The presence, role and clinical use of spermatozoal RNAs. Hum Reprod Update 19(6): 604-624.

82. Curry E, Safranski TJ \& Pratt SL (2011). Differential expression of porcine sperm microRNAs and their association with sperm morphology and motility. Theriogenology 76(8): 1532-9.

83. Kasimanickam V \& Kastelic J (2016). MicroRNA in sperm from Duroc, Landrace and Yorkshire boars. Sci Rep 6: 32954

84. Govindaraju A, Uzun A, Robertson L, Atli MO, Kaya A, Topper E, Crate EA, Padbury J, Perkins A \& Memili E (2012). Dynamics of microRNAs in bull spermatozoa. Reprod Biol Endocrinol 10(1): 82.

85. Lu J, Gu H, Tang Q, Wu W, Yuan B, Guo D, Wei Y, Sun H, Xia Y, Ding H, Hu L, Chen D \& Sha J (2016). Common SNP in hsa-miR-196a-2 increases hsa-miR-196a$5 \mathrm{p}$ expression and predisposes to idiopathic male infertility in Chinese Han population. Sci Rep 6:19825. 